\title{
A Cultural Framework of Care and Social Protection for Older People in India
}

\author{
Vanessa Burholt ${ }^{1} \mathbb{0}$, Rangasamy Maruthakutti ${ }^{2}$, and Carol A. Maddock ${ }^{1}$ \\ ${ }^{1}$ Centre for Innovative Ageing, College of Human and Health Sciences, Swansea University, Swansea, Wales, UK \\ ${ }^{2}$ Department of Sociology, Manonmanian Sundaranar University, Tirunelveli, Tamil Nadu, India
}

\begin{abstract}
This article applies a cultural political economy lens within a sustainable livelihood framework and examines how cultural norms and values as well as social protection amplify or attenuate livelihood shocks leading to care-home entry. We used framework analysis and higher-level interpretive analysis of data from interviews with 30 older care-home residents from three districts in Tamil Nadu, India, to understand the practices that allow the social welfare system to function alongside the beliefs and values legitimizing these practices. Results reveal a divergence between the value orientation of social-protection policy and cultural practices which constrains the choices available for care in later life and reinforces culturally constructed inequalities rather than protecting or remediating livelihood shocks and loss of assets.
\end{abstract}

Keywords: critical social policy, cultural political economy, residential care, pensions, caregiving, social support

This article examines how culture has influenced (and/or sustained) access to care and social protection for older care-home residents in Tamil Nadu, India, to date a neglected issue in research. Social protection and culture are studied within a sustainable livelihood framework. Within this framework, we consider public, private and civic organizations as transforming structures, while policies, legislations, institutions, conventions and culture (such as norms, values, and beliefs) are transforming processes. Together, they constitute a complex system that is part of the cultural-political economy and govern access to assets (financial, human, natural, physical, and social), and power, thus impacting on livelihood outcomes. From this perspective, the cultural-political economy (Biebuyck \& Meltzer, 2017) determines the extent to which a person has choices, has to make choices, or has no choice over the care they receive in later life.

In this article, we consider relocation to a care home as a specific outcome determined by the interrelationship between livelihood assets and the transformational role of social protection and culture. By applying a cultural political economy theoretical lens, we pose three research questions designed to determine the functioning of the social welfare system alongside the beliefs and values that legitimize it (Sewell, 1999). These questions are addressed by the analyses of qualitative data from interviews with 30 care-home residents in Tamil Nadu, India.

\section{Culture and Social Protection Within a Livelihood Framework}

Social protection comprises "public and private policies and programs undertaken by societies in response to various contingencies to offset the absence or substantial reduction of income from work" (United Nations Economic and Social Council, 2001, p. 4). Within a sustainable livelihood framework that "comprises the capabilities, assets (including both material and social resources) and activities required for a means of living" (Chambers \& Conway, 1992), social protection has the potential to be a "transforming structure" that ensures the sustainability of livelihoods. As a transforming structure, social protection could include effective preventative schemes designed to reduce vulnerability to shocks to livelihood assets (financial, human, natural, physical, and social), and remedial schemes to support recovery from shocks, or directly provide a means of living for those unable to secure this for themselves. Social protection does not include healthcare, which is generally addressed as a separate issue. It lies beyond this scope of this article to simultaneously consider health insurance and healthcare coverage as transforming processes (see, Burholt et al., 2020, forthcoming).

Social security is one component of social protection comprising social insurance and/or social assistance. In 
Europe, social protection has mainly relied on social insurance contributions from those engaged in labor force activities. However, social insurance is viable only in societies where a large proportion of the population is employed and contributes to the scheme. Contributions must match the financial outlay required to meet the needs of those not engaged in the labor force (e.g., for pensions, care-work compensation, unemployment, maternity/paternity, and disability benefits). In low- and middle-income countries (LMIC), where labor is often dominated by informal economic activities, social assistance schemes are intended to provide a safety net for the population not covered by social insurance. Social assistance is often means-tested (United Nations Department of Economic and Social Affairs (UNDESC), 2007).

The policies, programs, and activities that comprise social protection are "taken in response to levels of vulnerability, risk, and deprivation which are deemed socially unacceptable within a given polity or society" (Conway et al., 2000, p. 5, emphasis added). Where access to social protection is not universal, social norms are used to delineate the fundamental values that comprise "necessities of daily living" (e.g., access to assets such as housing, food, water, and clothing). Those lacking necessities of daily living or the financial means to purchase them are categorized as living in poverty and in a means-tested system are eligible to claim social assistance (Munro, 2008; United Nations Economic and Social Council, 2001).

The dominant cultural norms of a country contribute to the value orientation of social assistance but also shape the system of delivery of support. Many LMIC incorporate family and community-based care into their social protection policy. For these policies to function, they are based on "norms that are accepted by the masses, which will then subject themselves to its laws" (Hofstede, 2001, p. 243). However, community social protection "should not be seen as a substitute for public action in providing basic protection" (United Nations Economic and Social Council, 2001, p. 4), and it is important to establish whether policies function as expected.

The interaction between the cultural foundations of political decisions and the norms driving citizens' behaviors has been underplayed in research on sustainable livelihoods (De Haan \& Zoomers, 2005). Studies in LMIC rarely account for the impact of culturally defined statuses, which influence access to assets and (mis)recognition in policymaking. For example, changes in family structures, family values, and the migration of family members erode traditional forms of solidarity, increase the strain on families to provide support to older people, and may go undetected because of the dominant (mis)representation of the capabilities of families institutionalized in the political system. This in turn may impact older people's access to alternative forms of assistance and increase their vulnerability to poor livelihood outcomes such as destitution (Burholt \& Scharf, in press). There is little evidence of research in LMIC examining outcomes for older people who are unable to live up to the policy rhetoric and transgress cultural norms (e.g., when family support is not as robust as portrayed politically) (UNDESC, 2007).

\section{Social Protection in India}

In India, social protection for older people is covered by social insurance and social assistance. Social insurance schemes include the Employees' Provident Fund (EPF), Varishtha Pension Bima Yojana, and the Pradhan Mantri Vaya Vandana Yojana, which provide an assured minimum pension depending on the subscription amount (Agewell Foundation, 2019). Contributions to the EPF are obligatory for employers and employees in the private sector (in firms with more than 20 employees) and for civil servants, military personnel, and various public-sector organizations. However, only $6.5 \%$ of the workforce (26 million out of 400 million) have access to an EPF pension (Agewell Foundation, 2019).

Social assistance for older people is provided mainly through the Integrated Programme for Senior Citizens (IPSrC) and the Indira Gandhi National Old Age Pension Scheme (NOAPS). The IPSrC is intended to provide basic amenities for older people (e.g., food, shelter, and medical care) and is administered through grants for registered care homes and day centers paid directly to providers (Agewell Foundation, 2019). Under NOAPS, in 2018/2019 the Government of India (GoI) provided ₹ $200^{1}$ and ₹ 500 per month to older people $65-79$ and $\geq 80$ years, respectively, living in households registered as below the poverty line $(\mathrm{BPL})^{2}$, without physical assets (land or property), income or family support. Some state governments provide an additional payment: In Tamil Nadu, an additional ₹ 800 per month was paid to those eligible over 60 years.

In 2007, the Maintenance and Welfare of Parents and Senior Citizens (MWPSC) Act mandated that children with sufficient resources must provide support to older people

\footnotetext{
${ }^{1} ₹ 100$ (100 Indian Rupees) = approximately €1.22.

${ }^{2}$ BPL is defined by the Government of India as ₹ 26 a day (€0.32) in rural areas and ₹32 per day (€0.39) in urban areas. These guidelines are used by the Gram Panchayat (village or small town council) to select local beneficiaries, typically from a population of 1-5 villages, with a few thousand residents. See Markussen (2011).
} 
who were unable to maintain themselves. The Act was amended in 2018 to extend the network of relatives responsible for providing care to grandchildren and other relatives. In situations where support is not provided, older people can take relatives to a tribunal to obtain maintenance orders. Relatives who do not comply with maintenance orders may be fined or imprisoned. Because eligibility for NOAPS is based primarily on the availability of family to provide support, only a small proportion of the older population are covered by government social protection: $18.6 \%$ of the population over 65 years receive payments (Ministry of Rural Development Government of India, 2020).

\section{Culture in India: The Traditional Indian Family}

There are a variety of family forms in India, although the notion of a normative traditional Indian household and extended family underpins the social protection system in India. This "ideal" family form is purported to meet the social, economic, and emotional needs of its older people (D'Cruz \& Bharat, 2001).

The values of the traditional family include filial piety (respect and obligations toward parents) and familism (prioritizing family needs above all others) (Burholt et al., 2017). Marriage is considered a social duty to the family (Nanda, 2019), and married couples are expected to have children (Bhambhani \& Inbanathan, 2018). Voluntary childlessness is rare, and women who do not have children are stigmatized (Riessman, 2000). Childlessness is challenging in later life, as older people are expected to be supported by their sons. However, filial support is a fictive rhetoric as daughters-in-law usually end up being responsible for providing care and support to older household members (Das Gupta, 1999). When daughters marry, they relocate to their parents-in-law's household and are responsible for most of the daily household chores (Ugargol et al., 2016).

Because the primary expectation is that care in later life will be provided by the family, moving into a care home rarely is a positive choice. Living in a care facility is often stigmatized and interpreted as family abandonment (Brijnath, 2012).

\section{Research Questions}

In this article, we examine the transformative roles of culture and social protection for older people in India, through a cultural political economy lens. Using framework analysis and higher-level interpretative analysis of qualitative data from interviews with 30 older care-home residents in Tamil Nadu, India, we address the following research questions:

1. How have cultural norms and values amplified or attenuated the impact of livelihood shocks and contributed to care-home entry?

2. How has social protection aggravated or mitigated livelihood shocks and influenced care-home entry?

3. Is there evidence of divergence or convergence between the value orientation of social protection policy and cultural practices?

\section{Methods}

\section{Sample Location}

Tamil Nadu state is situated in southern India and covers $130,060 \mathrm{~km}^{2}$. According to the census, in 2011 Tamil Nadu had a population of 72 million, $88 \%$ of whom were Hindu. One-fifth of the population comprised scheduled castes (i.e., of the lowest caste, officially regarded as socially disadvantaged and considered "untouchable" in orthodox Hindu scriptures and practice). In 2011 , one-tenth $(\approx 7.2$ million persons) of the population in Tamil Nadu were $60+$ years old, which greater than the proportion of older people in the overall population of India (8.6\%).36\% of the older population living in rural areas of Tamil Nadu were literate compared to $65 \%$ in urban areas. Furthermore, $42 \%$ of older men were dependent on others in rural areas compared to $33 \%$ in urban areas. Across both rural and urban areas, $81 \%$ of older women were dependent on others (Government of India Ministry of Statistics and Programme Implementation, 2016).

\section{Sampling Procedures}

Care homes were selected from three southern districts in Tamil Nadu: Thoothukudi, Tirunelveli, and Kanyakumari (Figure 1). A mapping exercise located 43 care homes: 13 in Thoothukudi, 11 in Tirunelveli, and 18 in Kanyakumari. We used the ratio of fee-paying to free-care homes in each district and the size of the care homes to inform our sampling strategy and to obtain (as far as possible) a gender-balanced sample of 10 people in each district (Table 1). Participants were randomly selected from lists of residents.

\section{Data Collection}

Face-to-face guided in-depth interviews (17-70 minutes; $M=34$ minutes) were conducted in Tamil with 30 residents 


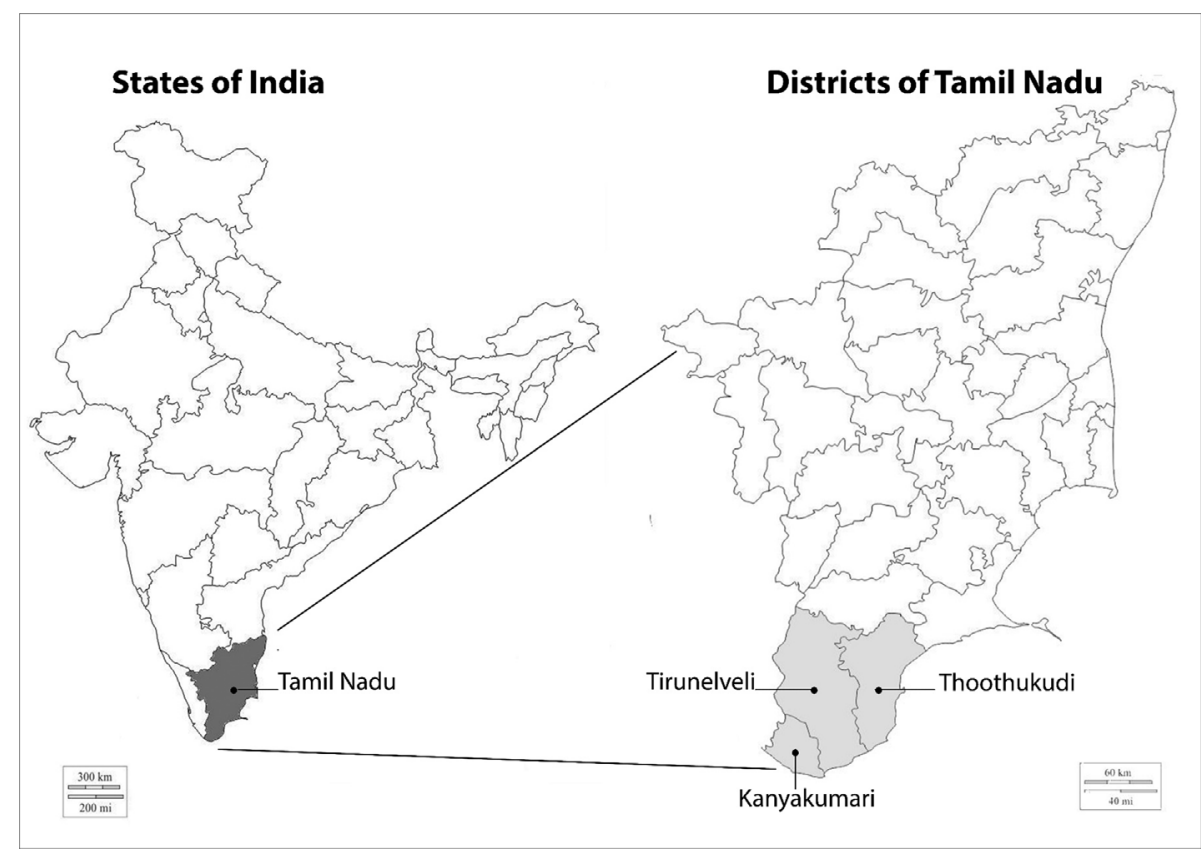

Figure 1. Map of the states of India showing the location of Tamil Nadu and map of Tamil Nadu showing location of selected states.

Table 1. Sample of residents in care home in three districts of Tamil Nadu

\begin{tabular}{|c|c|c|c|c|c|c|c|}
\hline \multirow{2}{*}{$\begin{array}{l}\text { District: } \\
\text { Type of care home }\end{array}$} & \multicolumn{2}{|c|}{ Thoothukudi $(n=10)$} & \multicolumn{2}{|c|}{ Tirunelveli $(n=10)$} & \multicolumn{2}{|c|}{ Kanyakumari $(n=10)$} & \multirow[b]{2}{*}{ Tota } \\
\hline & Fee-paying & Free & Fee-paying & Free & Fee-paying & Free & \\
\hline \multicolumn{8}{|l|}{$\overline{\operatorname{Sex}}$} \\
\hline Male & 2 & 3 & 0 & 5 & 2 & 3 & 15 \\
\hline Female & 0 & 5 & 2 & 3 & 2 & 3 & 15 \\
\hline Total & 2 & 8 & 2 & 8 & 4 & 6 & 30 \\
\hline
\end{tabular}

in the care homes between January and May 2018. The interviews were recorded, transcribed, translated by a third party into English, and anonymized. Pseudonyms are used throughout the article.

\section{Analysis}

We used framework analysis to analyze the data (Ritchie \& Spencer, 2002). Familiarization, conceptual and cultural understanding of the interviews were clarified during several team meetings in Tamil Nadu (VB, RM, RA, SP, RH). The first version of the coding index, comprising top-level headings for themes and heavily rooted in a priori issues (i.e., sustainable livelihood assets), was agreed during these meetings. In the UK, two members of the research team (VB, CAM) undertook coding, indexing, and charting the data. The index was applied to a few transcripts during which categories (subthemes) were identified and refined. We then systematically applied the resulting index to the text in NVivo Version 12. Data were charted (VB, CAM) into a framework that provided a decontextualized descriptive account of the data concerning livelihood assets, shocks, and livelihood outcomes for each case.

Themes representing transforming structures and processes were derived from higher-level interpretive analysis concerning what was inferred from the interviews. We (VB) also did an intuitively derived thematic content analysis (Wertz et al., 2011) of the impact of cultural norms, values, traditions, religion, and political-economic structures, policies, and institutions on the "choice sets" available to participants and added to the framework for each case.

We (VB) developed schematic diagrams and used them alongside the charted material to capture commonalities of experience across cases and to group interviews (Ayres et al., 2003). We created chronological explanatory summaries capturing the complexity of experiences for each participant (Polkinghorne, 1995).

The first interpretation of data concerning the research questions was undertaken in the UK (VB). Other team members in Tamil Nadu, India, and the UK (RM, CAM, URK) 
Table 2. Ranking of main groups and subgroups of participants from highest to lowest order of public visibility of deviation from cultural norms, and number classified in each

\begin{tabular}{|c|c|c|c|c|}
\hline & Main group & & Subgroup & $N$ \\
\hline \multirow[t]{2}{*}{ I } & No children & $\mid A$ & Never married & 5 \\
\hline & & IB & Once married & 4 \\
\hline \multirow[t]{2}{*}{$\|$} & Daughters only & $\| A$ & No sons & 7 \\
\hline & & IIB & Sons unavailable & 2 \\
\hline \multirow[t]{2}{*}{ III } & Poor relationships & $\| \mathrm{A}$ & Abusive or neglectful & 4 \\
\hline & & $\| \mathrm{IIB}$ & Weakened by life events & 3 \\
\hline \multirow[t]{2}{*}{ IV } & Family lack capacity to meet needs & IVA & Health & 3 \\
\hline & & IVB & Psychosocial & 2 \\
\hline
\end{tabular}

were used as a sounding board to check the persuasiveness of the analysis and to provide different ways of interpreting the research phenomenon (Hunter et al., 2002).

\section{Results}

We identified four main groups of participants based on the key features of their care-home trajectories (Table 2). We ranked the groups according to the visibility of cultural transgression in everyday life because condemnation for nonconformity is more likely when a deviation is observable (e.g., never married) than when hidden from view (e.g., lack of emotional support to alleviate loneliness). Several participants fell into more than one group (e.g., had only a daughter who was unable to provide care and an abusive son-in-law). In these instances, participants were classified in the highest-ranked category.

The results, addressing each research question in turn, are presented in a series of seven exemplars comprising schematic diagrams of livelihood trajectories and textual chronological explanatory summaries drawn from subgroups IA-IIA and IIIA, supplemented with excerpts from other interviews to illustrate particular topics (such as access to pensions). These exemplars capture examples of familial caregiving capacity that are similar to the accounts in groups IVA-B.

\section{The Transforming Role of Cultural Values and Norms}

Losing the capacity to work and/or care for oneself were significant life events that precipitated relocation to a care facility and were common to most participants. However, these experiences were transformed by culture. Specifically, the transgression of values and norms central to the traditional Indian family (marriage, child-bearing, and filial support) influenced participants' access to social and material assets in later life and significantly contributed to their moving into a care home.

Five participants had never wed, despite the strong normative expectation. Each unmarried participant faced barriers that prevented them from taking a spouse. These constraints were related to the stigma associated with disability $(n=2)$ and being orphaned $(n=1)$. Two participants had a high likelihood of undisclosed homosexuality. All five unmarried participants were childless.

Dev's (72 years, unmarried) parents died when he was 10 days old, and he was raised in an orphanage (see Figure 2). After completing his Secondary School Leaving Certificate at the age of 16, he had to find employment. He worked as a kitchen porter in a hotel for 30 years, during which time his work colleagues urged him to find a wife. "While I was working at that hotel, they used to advise me to marry. They used to say that I would suffer in later life. I didn't marry. I didn't have parents." As the selection of a marriage partner involves the consideration of the social class and cultural compatibility of prospective spouses by examining their family history (Nanda, 2019), individuals who are unable to identify the caste, class, and religion of their parents cannot demonstrate the "decency" of their family background and are omitted from the pool of eligible partners.

Following the closure of the hotel, Dev worked in various menial positions, finally securing a job as a watchman at a children's home where he worked until his health deteriorated and the proprietors asked him to leave.

They said that I was struggling to do things and asked me to take rest. I took rest for 10 days. I had to sleep outside there. ... I had to sleep in severe cold, dew, and rain. There was a room like where you keep the motor [a garage]. I had to do everything in that room.

Because Dev was unemployed, had no source of income, accommodation, or family support, the proprietors secured him a place in a care home for destitute older people.

Whereas Dev recognized that his status as orphan limited his opportunity to marry, Rina (age unknown, unmarried) 


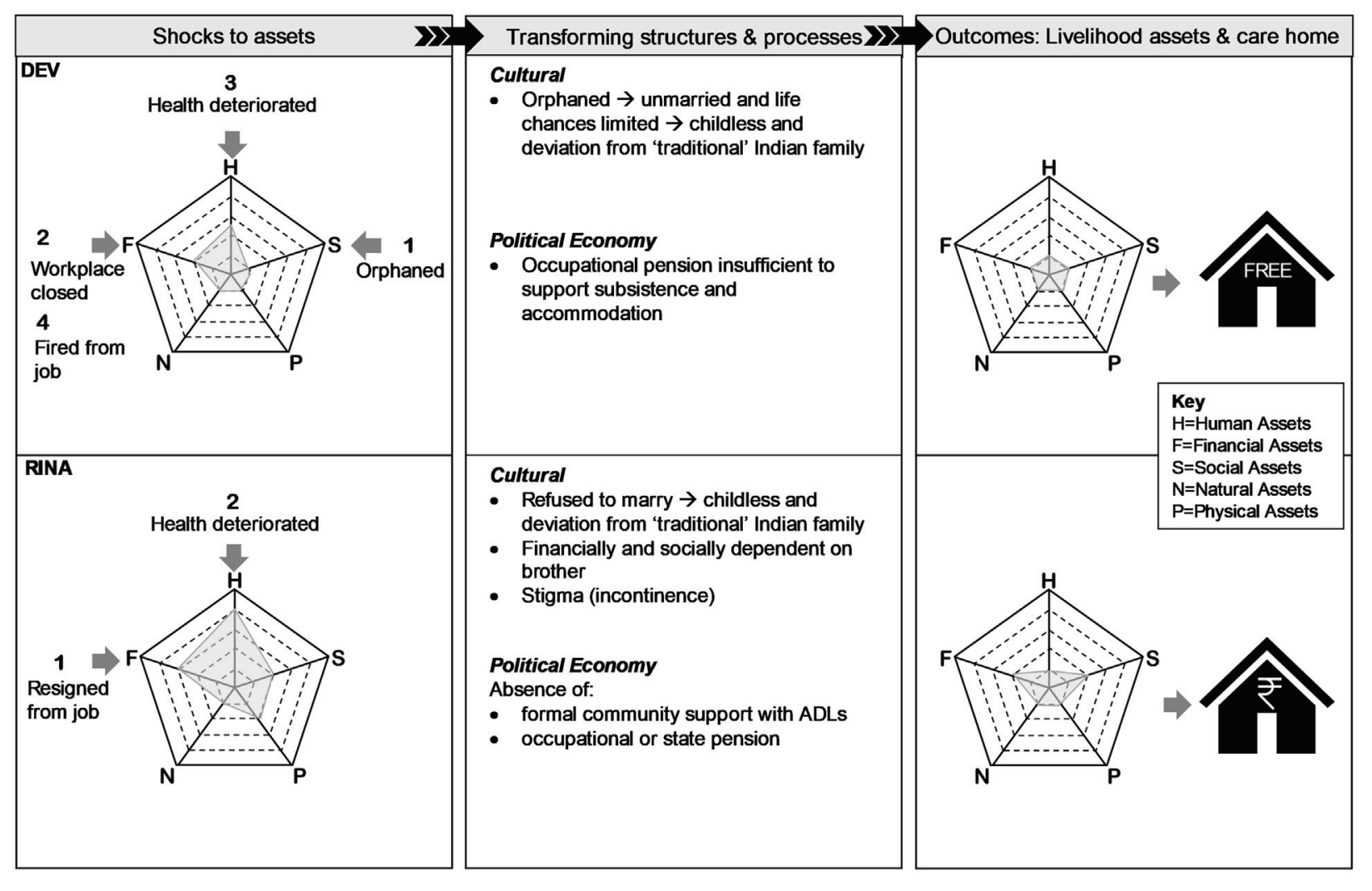

Figure 2. Livelihood framework care-home trajectory for never married childless participants, group IA: Dev and Rina.

said, "I despised marriage. I decided not to marry" (see Figure 2). This (and other comments) may suggest that she was a feminist or a lesbian. Rina worked for more than 20 years as a teacher but resigned because she felt it was pointless earning money without children to spend it on. Rina rented a house next door to her younger brother, whom she described as having "all the comforts of life." As an unmarried woman, she was reliant on the social relationships with her closest male family member. She was not permitted to visit other people because it was socially undesirable and "it might be a disgrace to my younger brother." Rina employed a maid to do the household chores. Before moving to a care home, her health deteriorated substantially, and she was confined to bed. Although the maid provided help changing her incontinence pads, her daily visits became more erratic, and "she used to come when it was convenient for her." Rina's brother moved her to a care home because she was perceived as a "trouble" to his family. Her incontinence and the associated odors conferred a particular cultural stigma on the household (Brijnath \& Manderson, 2008), and she was labeled as a socially undesirable relative.

Dev and Rina stem from different socioeconomic backgrounds, but because neither had married, they had no children to provide them with support in later life.
This salient feature was also shared by participants who had married but remained childless, such as Deepak and Joti.

Deepak (68 years, widowed) had been engaged in dailywage labor in agriculture or construction since the age of 23 (see Figure 3). He was married, but his wife was unwell. Because he received irregular, low wages, he struggled to pay for her medicines. Deepak had a stroke when he was 50 , and a year later was paralyzed, preventing him from working or looking after himself. "For one year, my wife supported me to move around. But then my limbs became so weak that I couldn't walk anymore." Deepak's daily needs were met by his wife, until her health deteriorated and they had to pay local children to fetch water, do the shopping and cleaning, etc. With no household income, they were reliant on charitable donations from visitors. Five years after Deepak was incapacitated, his wife passed away in the hospital. Deepak sold the house to pay her hospital fees and moved into makeshift accommodation closer to his brother's house to receive care.

I don't have a house of my own to dwell in. I don't have even a cent of land. I was there just like a street dweller. ... I was lying there like a dog. It was a kennel covered with a tarpaulin. 


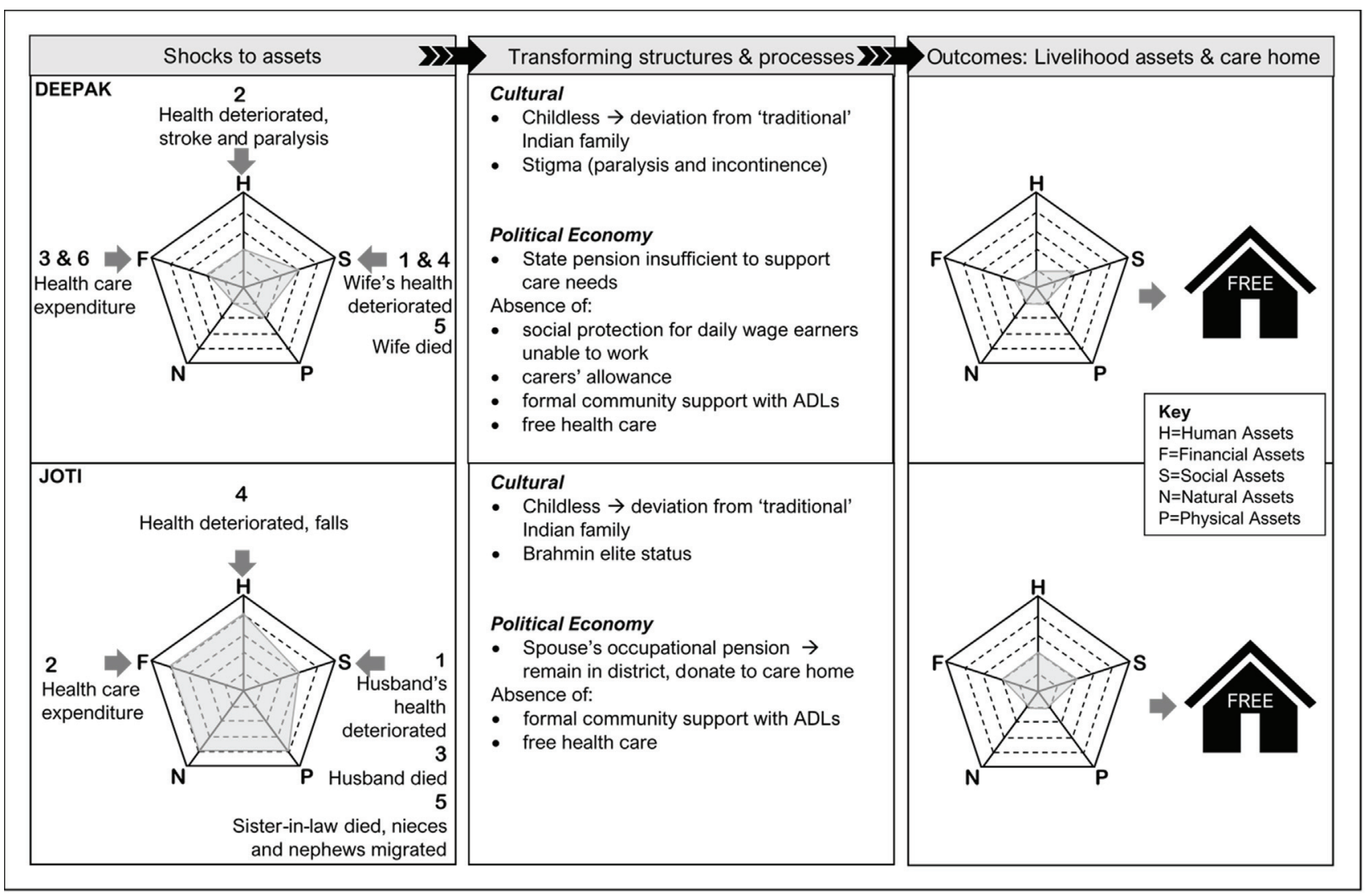

Figure 3. Livelihood framework care-home trajectory for married childless participants, group IB: Deepak and Joti.

Deepak's brother helped him with bathing and washing his clothes. However, as a daily wage laborer, he frequently had to work away from home. Under these circumstances, a young local man bought Deepak food and disposed of his feces and urine. Because incontinence confers a particular cultural stigma (see above), even distant blood kin did not want to provide care. Deepak acknowledged that "they don't want to see me lying down like this. They [show me] disdain... There are lots of problems in taking care of such a person like me." Recognizing his plight, the owner of the village pharmacy suggested that Deepak move to a care home.

Joti (85 years, widowed) married a policeman when she was 16 (see Figure 3). Her husband was diagnosed with tuberculosis, which may have affected his fertility, as they remained childless (Kumar, 2008). The couple was wealthier than many other families, but out-of-pocket health expenditure on treatment substantially reduced their financial assets. Joti lived alone for 12 years after the death of her husband. Following a fall, she moved to live closer to her widowed sister-in-law. Another fall led to a substantial deterioration in her health, and she needed help with shopping, cooking, and other household tasks. Her neighbors brought water and prepared her meals, and Joti employed a maid to help around the house. After her sister-in-law passed away, Joti chose to move to a Brahmin care home as she didn't think she would be able to manage alone, for example, when her maid took holidays.

Childless older people struggled to receive the care they needed in the community. However, participants with daughters were in a similar position as they lacked filial support in later life. Asking for and/or receiving care from a daughter would transgress cultural norms, which is illustrated in Rishi's story.

Rishi (83 years, married) had four well-educated daughters (see Figure 4 ). He ran a chit fund: a savings and credit association system widespread in India. He paid for two of his daughters' weddings before he hit financial difficulties. "A lot of money was going around. Those who got money from me did not pay it back. I could not give money to others. I had borrowed money from the bank and I could not pay it back." Following bankruptcy, Rishi was unable to pay for the weddings of his two remaining unmarried daughters, but drew on financial support from his extended family to arrange their marriages.

With no accommodation, Rishi and his wife temporarily moved in with a daughter until he secured a job as a cashier in a distant city hotel. However, the pay was so poor that he could not afford rent. Rishi lived at his place of work and sent his wages to support his wife, who alternately lived with each of the two youngest daughters. Rishi's daughters asked 


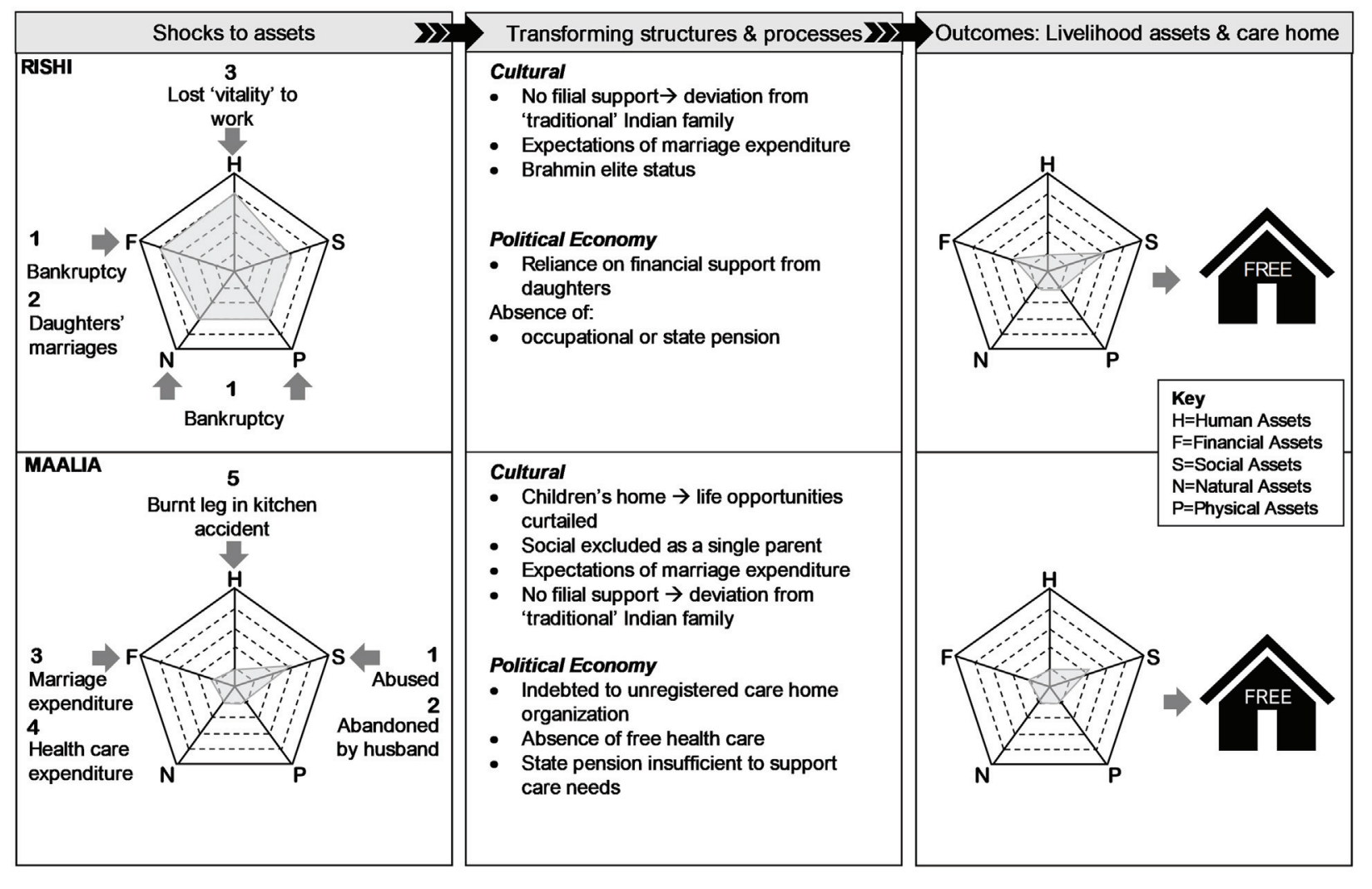

Figure 4. Livelihood framework care-home trajectory for participants with daughters only, group IIA: Rishi and Maalia.

him to retire when he "became very old" and could not work with so much "vigor." He moved to a Brahmin care home with his wife. None of his daughters could provide care as they had competing care demands (parents-in-law and children to support), but they all financially supported their parents through donations to the care home. Rishi explained the different expectations concerning support from sons and daughters.

One should not leave one's parents in old-age homes. They [sons] should take care of their parents. Those who have money employ servants at home to look after their parents ... The daughter can also [provide care]. But we cannot compel her. We marry her off to some other family. The son-in-law's parents are there. Should she look after them or us? We cannot compel the daughter. We can compel the son.

\section{The Transforming Role of Social Protection}

Older people who had accrued enough financial assets throughout their lives, or who had access to alternative sources of income other than a wage or salary, were able to retire, while others who were less financially secure had to work until they were physically unable to continue. The physical inability to work had an impact on financial assets, which was mitigated, for some, by alternative family income or an occupational pension, but rarely from NOAP. Relief for the lack of livelihood assets was also met through care-home provision. However, most care homes relied on private funding and charitable donations rather than government support through the IPSrC.

Joti and Dev received occupational pensions, ₹2,000 and ₹800, respectively, and used these to fund their upkeep in the free-care homes. Some participants without an income, such as Rina and Rishi, relied on their family to pay for the care home. Rina believed that she was ineligible for an EPF pension as she had resigned from her post as a teacher. She did not seem unduly worried that she had no income. "I don't have any intention to know about such things," as her brother was paying the care-home fees. Although Rishi had lost his financial assets through bankruptcy, he was ineligible for a state pension as he had financially solvent daughters who were making contributions to the home.

In some cases, the families were impoverished and were unable to provide either physical care or financial support to older relatives, or the older person did not have any family or other assets on which to draw. In these cases, a state pension (NOAPS) should have been available. However, 
obtaining such a pension is hampered by a lack of knowledge about how to claim one, a lack of support to make a claim, and inconsistencies in the application of eligibility criteria. Some participants were aware that there were pensions but had no idea how to apply. For example, two participants noted: "Two grandpas and a grandma near my house were getting it. But I don't know how they got it" (female, 75 years, widowed) and "I didn't get any. They say it is there. I don't know about it. I gave up on such efforts" (female, 77 years, widowed). Other participants mentioned difficulties in completing application forms because of illiteracy or low levels of education. For older people lacking familial support and living in poverty, this was compounded by the fees charged to help with completing an application, or the perception that to secure a pension one would need to travel and bribe officials.

\section{I don't have that much of education. I can get help from others for writing. I cannot do that myself. So I would have to get somebody's help. I would have to take that person to offices. I would have to meet the village admin- istrative officer and others. Just meeting the expenses would not suffice. They would demand bribe ... You have to run here and there. ... If you want to get a pension, you will have to spend ₹3000. Then only you will get it. (male, 72, separated).}

The effectiveness of social protection relies on its reaching the poorest poor, but also its adequacy in making up for deficits in livelihood assets (Asri, 2019). Both Deepak and Maalia (see below) received a state pension because their families' economic status made support untenable. Maalia's daughter was struggling to look after her own children: "How can she help me? She could give me maybe ₹5 or ₹10. She is doing housemaid work." Deepak's brother was a wagelaborer, for whom providing care would entail losing productive labor hours (Brinda et al., 2014). However, the state pension was not sufficient to cover accommodation, subsistence, health, and care needs in the community. Relocation to a care home was often the only option available to older people without any other income.

The care-home sector provides succor for older people without alternative sources of financial or social support. In 2018-2019, the Government of India funded 51 institutions across Tamil Nadu through the IPSrC. This represented, on average, financial support for two care homes per district, except in seven districts, which did not receive any funding. 41 care homes were identified in the three districts included in this study which were mainly being funded from nongovernmental sources (i.e., private paid care or charitable donations). Some facilities were unregistered and, as such, were not subject to state regulation or inspection. This potentially left residents vulnerable to organiza- tional exploitation and abuse, as experienced by Maalia, who spent most of her life in care facilities run by a religious organization.

As a child, Maalia (65 years, separated) moved to a children's home to avoid her step-mother's abusive behavior. "I went on my own, not able to bear the tortures of my stepmother" (see Figure 4). Maalia married but was abandoned by her husband when she was 6 months pregnant. As a single mother, she was marginalized and discriminated against within the community (Sinha et al., 2016). Living in extreme poverty, Maalia left her daughter in a children's home, moved into a women's refuge, and worked in the kitchen of the orphanage she had been raised in.

Maalia borrowed ₹3,000 from the organization to arrange her daughter's marriage. To recover the wedding debt, the proprietors retained her salary ( $₹ 500$ per month) for more than two decades. At that time, Maalia required significant healthcare expenditures to treat a work-related burn, sustained in the kitchen. Without any personal financial assets of her own, the organization paid ₹27,000 for hospital fees. Maalia continued to work to pay off the debt. Eventually, her sight deteriorated, and she was told that she needed an eye operation. "They took me to the government hospital. They said that I should undergo an operation. But I didn't have any money." Unable to work to pay back another loan, Maalia requested moving to a care home for older people located within the cluster of facilities. "I begged the doctor to leave me at the home [for older women]."

The cultural pressure to arrange a marriage for her daughter resulted in Maalia's indebtedness to the care organization. Publicly, the organization's website notes that they make every effort to find suitable grooms for female residents and meet all of the associated costs. Instead, the modus operandi emulated a hybrid between a workhouse and debtors' prison (Driver, 1993), from which Maalia was unable to escape.

\section{Divergence Between Cultural Values and Social Protection Policy}

Social protection has the transformational potential to mitigate shocks to human assets and the resulting impact on livelihood outcomes. However, there was divergence between policy assumptions in the MWPSC Act and the experiences of older care home residents. First, the policy idea that the existence of a traditional family equates with the ability to provide care and meet the social, economic, and emotional needs of older people did not converge with the lived reality of older people from poor families, or with families in which relationships were abusive or weak. Second, the eligibility criteria for NOAPS highlight the differences between cultural and political expectations concerning support from relatives in the extended family. 


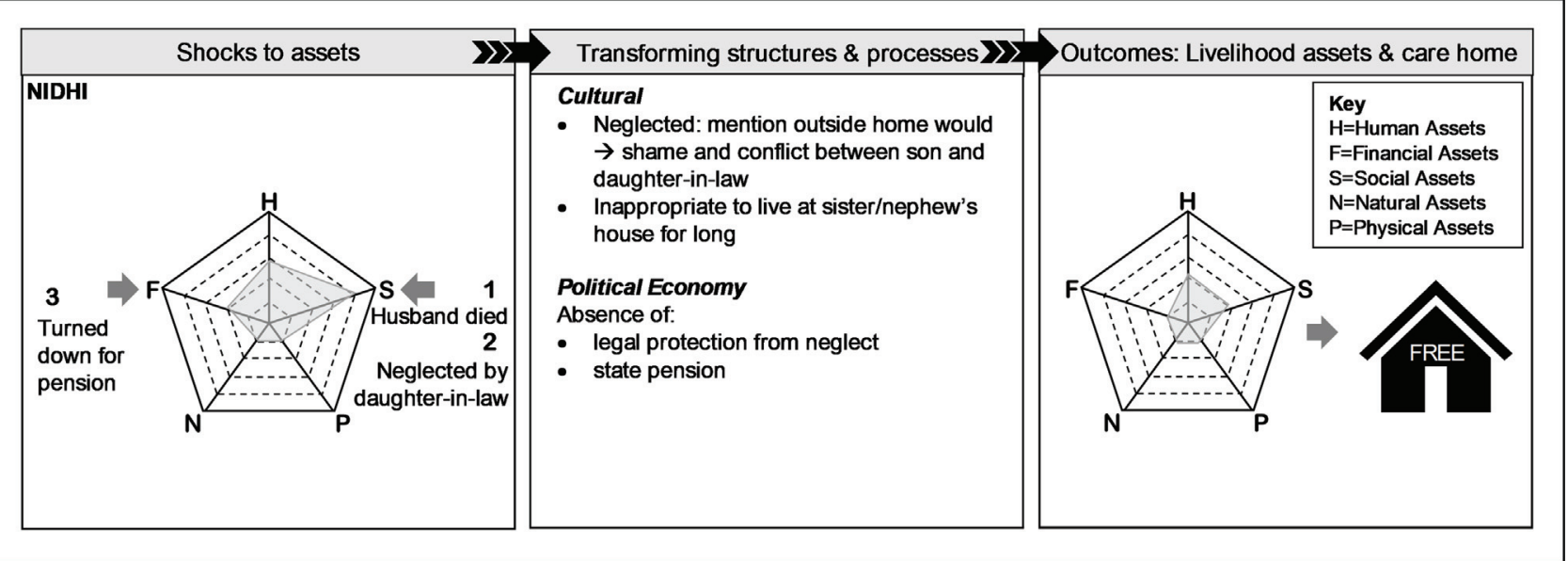

Figure 5. Livelihood framework care-home trajectory for a participant with a poor filial relationship, group IIIA: Nidhi.

The difference between the political values embedded in the social protection system and actual cultural practices meant that, in some cases, familial care could not be accessed without transgressing cultural norms and creating shame, or enduring financial hardship.

In traditional Indian families, many of the poorest households do not have the financial means to support older relatives. It has been estimated that between one-half and three-fifths of the poorest households in India are not registered as BPL (Drèze \& Khera, 2017; Ram et al., 2009). Older people who have families unregistered as BPL are unable to claim a pension.

Some older people who had families in which filial support should have been available (according to the MWPSC Act) also encountered difficulties receiving adequate care because they were neglected or abused. For example, Nidhi (80 years, widowed) moved in with her son after the death of her husband but was neglected (see Figure 5). " $M y$ daughter-in-law wouldn't even bother to ask if I had eaten. After returning from work, my son would first ask me if I had eaten. My grandson would reply that grandma hadn't eaten. I couldn't endure that." To receive support, Nidhi moved in with her sister.

Participants who had abusive or weak relationships with sons were in a similar position to participants who had no filial support. However, there was a difference between the expectations of support through the extended family as envisaged in the MWPSC Act and actual cultural expectations. For example, Rishi noted the difficulties associated with asking for, or receiving, care from a daughter in light of competing care demands, while Deepak and Rina's care needs outstripped the caregiving expectations concerning "body work" from distant blood kin. Nidhi lived in her nephew's house for 4 years, during which time she applied for a pension. "It was approved. When they came for verification, the neighbors told them that I was living with my relatives.
So they went back and informed [the administrator] that I was not eligible." Rather than providing Nidhi with support to live independently, the social protection system exacerbated the situation by reinforcing dependency on her sister in a living arrangement she felt was not culturally appropriate. "Because it was not proper to stay there for a long time, I met a Father and requested help [to move to a care home]." Other participants also moved into a care home to avoid an abusive or a neglectful relationship, and/or to eschew the transgression of living with and receiving support from siblings or other distant relatives.

\section{Discussion}

The life-course trajectories described here were underpinned by the culturally defined position one holds in society, for some ascribed at birth or in childhood (e.g., orphaned, born with a disability); by their sexuality, economic position (living in poverty), or caste and religion (e.g., Brahmin). Other lives were redefined in adulthood, with a majority of those living in residential care having families that deviated from the socially ideal traditional joint family. In both childhood and adulthood, key features of the political economy reinforced culturally constructed inequalities rather than protecting or remediating livelihood shocks and loss of assets.

Socioeconomic status contributed to the decision to move to a care home. For example, Joti and Rishi were both Brahmin, had access to independent or familial financial assets, and made a positive choice to move. Brahmin is the highest-ranking of the four Hindu varnas/castes or social classes in India and confers a particular elite status. The Brahmin care home purported to be a free-care home for destitute older people but avoided the stigma associated 
with pauperism by referring to the facility as an ashram. While all residents interviewed in this facility had no filial support, they were not devoid of assets as they (or their families) gave regular and often sizable donations to the home. However, social protection failed to provide for older people without such an elite status. Many care-home residents had been excluded from key resources, protection from harm, and a choice over where they live - and over whom they received support from in later life.

The transgression of cultural values can be dealt with through informal community sanctions such as ostracism (e.g., marginalization of single parents such as Maalia). Societal failure to produce conformity that maintains the social order and the power structure of the politicaleconomic order often requires some form of social control enforced through formal sanctions, such as fines and/or imprisonment. One interpretation of the MWPSC Act is that it dictates sanctions for nonconformity to the traditional supportive family, defining what is, and who are labeled as, deviant or criminal, and assigning social protection only to the "deserving poor." To receive a pension, older people must demonstrate impoverishment and the lack of family support. Even if these criteria are met, bureaucratic systems are difficult to navigate, pensions are difficult to secure, and may require sufficient financial assets to bribe officials. Furthermore, it is not possible to survive solely on a pension (Vera-Sanso, 2004) as it does not provide enough security for subsistence in the community. While the Act has made strides in protecting older people from abuse and providing for those without family, there are flaws inherent in the system (HelpAge India, 2017).

First, requesting or expecting family support is particularly problematic for older people with poor relatives. Millions of people engaged in the informal wage sector do not receive a decent living wage, and many poor households are not registered as BPL. Time constraints have been cited in other studies as one of the greatest barriers to providing care to older people (Bahtt et al., 2017). Presently, there is no financial support for kin-carers in India. This is especially important in low-income families, where the provision of care entails the loss of revenue (Brinda et al., 2014). Unless social protection includes provisions for a living wage, increases in the number of poor households registered as BPL, and the provision of financial support for kin-carers in low-income families, the care needs of older people will continue to be neglected in poor households.

Second, the Act has not properly understood public morality concerning the responsibilities of relatives, especially how older people negotiate commitments to and from kin other than sons. Indian culture establishes rules defining what it is morally permissible to do, and support in later life has been predominantly the responsibility of sons. Support from relatives other than sons is rare and is not part of the cultural expectations (Vera-Sanso, 2004). Thus, to receive a pension, older people must be willing to transgress cultural norms.

Third, when families are unable or unwilling to provide care, an older person is supposed to initiate a tribunal to receive a maintenance order. Families that fail to comply with a maintenance order are fined or imprisoned. This process assumes that older people (1) have knowledge of the Act and (2) are willing to criminalize relatives potentially bringing shame on the family. Research suggests that these two assumptions are rarely met (HelpAge India, 2017).

By applying a cultural political economy lens, our results suggest that the MWPSC Act is a discursively selective imaginary (Jessop, 2010), shaping the lived experiences of older people in Tamil Nadu by constraining the receipt of financial assets to maintain independence. The choices available to older people with kin are somewhat unpalatable: transgress cultural norms by living with their daughters or other relatives; criminalize the family; endure destitution (and death) (Harriss-White, 2005), or become an "inmate" in a care home.

Central to the qualitative paradigm is that older people's experiences are situated within historical and social contexts. Consequently, there are multiple variations in the life-course trajectories across India that contribute to care-home entry, and some specific salient features may not have been captured by our study in Tamil Nadu. However, there is good reason to believe that (1) insufficient BPL registration, the lack of a living wage, or the lack of financial support for caregivers; (2) divergence between the value orientation of social policy and culture (in terms of seeking nontraditional family support, enduring abusive family relationships, or having no family), and (3) difficulties inherent in the Tribunal process are major contributing factors to care-home entry elsewhere in India.

In India, care homes are necessary to support older people who have no family and/or have care needs that exceed family caregiving capabilities. Private-sector care homes are accessible to those that can afford them. For older people without financial assets, care homes are provided mainly through the charitable sector. The limited number of statefunded care homes does not provide a realistic alternative to familial care (Vera-Sanso, 2004). Within the imaginary of MWPSC Act, care homes funded by IPSrC are structurally selective institutions to deal with destitute older people. State provision may be aimed at reducing threats to civil order (Rosenheim, 1966) rather than providing a safety net for older people without alternative means of support.

We noted in the Introduction that policy-making relies on "norms that are accepted by the masses, which will then subject themselves to its laws" (Hofstede, 2001, p. 243). Culture has the potential to impede the public policy process (Pellissery, 2008): the plausibility of the imaginary 
surrounding the deployment of the traditional Indian family to provide care and support to older people depends on resonance with cultural expectations. A mismatch between lived experience and policy rhetoric can undermine public perceptions of distributive justice and the legitimacy of government. Because the proportion of older people in the Indian population is on the increase, shortfalls in the social protection system will necessitate growth in the care-home sector, heightening the visibility of the incongruence between the political imaginary and cultural norms, values, and practices. Therefore, it may be time for the Government of India to reconsider the cultural appropriateness of the MWPSC Act, to ensure a sufficient level of resources is distributed to meet the true needs of older people.

\section{References}

Agewell Foundation. (2019). Status of social security and social protection in India (with special focus on older persons). https:// social.un.org/ageing-working-group/documents/tenth/SocialSecurity-in-India-2019.pdf

Asri, V. (2019). Targeting of social transfers: Are India's poor older people left behind? World Development, 115, 46-63. https:// doi.org/10.1016/j.worlddev.2018.11.001

Ayres, L., Kavanaugh, K., \& Knafl, K. A. (2003). Within-case and across-case approaches to qualitative data analysis. Qualitative Health Research, 13(6), 871-883. https://doi.org/10.1177/ 1049732303013006008

Bahtt, A. N., Joseph, M. R., Xavier, I. A., Sagar, P., Remadevi, S., \& Paul, S. S. (2017). Health problems and healthcare needs of elderly: Community perspective from a rural setting in India. International Journal of Community Medicine and Public Health, 4(4), 1213-1218. https://doi.org/10.18203/2394-6040. ijcmph20171351

Bhambhani, C., \& Inbanathan, A. (2018). Not a mother, yet a woman: Exploring experiences of women opting out of motherhood in India. Asian Journal of Women's Studies, 24(2), 159-182. https://doi.org/10.1080/12259276.2018.1462932

Biebuyck, W., \& Meltzer, J. (2017). Cultural political economy. In R. A. Denemark \& R. Marlin-Bennett (Eds.), The international studies encyclopedia. Wiley-Blackwell.

Brijnath, B. (2012). Why does institutionalised care not appeal to Indian families? Legislative and social answers from urban India. Ageing \& Society, 32(4), 697-717. https://doi.org/ $10.1017 / S 0144686 \times 11000584$

Brijnath, B., \& Manderson, L. (2008). Discipline in chaos: Foucault, dementia and aging in India. Culture, Medicine, and Psychiatry, 32(4), 607-626. https://doi.org/10.1007/s11013-008-9111-5

Brinda, E. M., Rajkumar, A. P., Enemark, U., Attermann, J., \& Jacob, K. S. (2014). Cost and burden of informal caregiving of dependent older people in a rural Indian community. BMC Health Services Research, 14(1), 207. https://doi.org/10.1186/ 1472-6963-14-207

Burholt, V., Dobbs, C., \& Victor, C. (2017). Social support networks of older migrants in England and Wales: The role of collectivist culture. Ageing \& Society, 38(7), 1453-1477. https://doi.org/ $10.1017 / S 0144686 \times 17000034$

Burholt, V., Maruthakutti, R., \& Maddock, C. A. (2020). Decisionmaking and choice or sine qua non? Care home entry in Tamil Nadu. In A. Bailey, M. Hyde, \& K. S. James (Eds.), Living arrangements and care for older adults in India. Policy Press.
Burholt, V., \& Scharf, T. (2020). Critical social gerontology and rural ageing. In M. Skinner, R. Winterton, \& K. Walsh (Eds.), Rural gerontology: Towards critical perspectives on rural ageing. Routledge.

Chambers, R., \& Conway, R. (1992). Sustainable rural livelihoods: Practical concepts for the 21 st century. Institute of Development Studies, University of Sussex.

Conway, T., de Haan, A., \& Norton, A. (2000). Social protection: New directions of donor agencies. Department for International Development.

Das Gupta, M. (1999). Lifeboat versus corporate ethic: Social and demographic implications of stem and joint families. Social Science \& Medicine, 40, 173-184.

D'Cruz, P., \& Bharat, S. (2001). Beyond joint and nuclear: The Indian family revisited. Journal of Comparative Family Studies, 32(2), 167-194. https://doi.org/10.3138/jcfs.32.2.167

De Haan, L., \& Zoomers, A. (2005). Exploring the frontier of livelihoods research. Development and Change, 36(1), 27-47. https://doi.org/10.1111/j.0012-155X.2005.00401.x

Drèze, J., \& Khera, R. (2017). Recent social security initiatives in India. World Development, 98, 555-572. https://doi.org/ 10.1016/j.worlddev.2017.05.035

Driver, F. (1993). Power and pauperism: The workhouse system, 1834-1884. Cambridge University Press.

Government of India Ministry of Statistics and Programme Implementation. (2016). Elderly in India: Profile and programmes 2016. http://mospi.nic.in/sites/default/files/publication_reports/ Elderlyinlndia_2016.pdf

Harriss-White, B. (2005). Destitution and the poverty of its politics with special reference to South Asia. World Development, 33(6), 881-891. https://doi.org/10.1016/j.worlddev.2004.09.014

HelpAge India. (2017). Preliminary study on the effectiveness of the "Maintenance and Welfare of Parents and Senior Citizens Act 2007". HelpAge India.

Hofstede, G. (2001). Culture's consequences: Comparing values, behaviors, institutions, and organizations across nations. Sage.

Hunter, A., Lusardi, P., Zucker, D., Jacelon, C., \& Chandler, G. (2002). Making meaning: The creative component in qualitative research. Qualitative Health Research, 12(3), 388-398. https:// doi.org/10.1177/104973202129119964

Jessop, B. (2010). Cultural political economy and critical policy studies. Critical Policy Studies, 3(3-4), 336-356. https://doi. org/10.1080/19460171003619741

Kumar, R. (2008). Reproductive tract tuberculosis and male infertility. Indian Journal of Urology, 24(3), 392-395. https:// doi.org/10.4103/0970-1591.42624

Markussen, T. (2011). Inequality and political clientelism: Evidence from South India. The Journal of Development Studies, 47(11), 1721-1738. https://doi.org/10.1080/00220388.2011.561330

Ministry of Rural Development Government of India. (2020). National Social Assistance Programme disimbursement abstract. Ministry of Rural Development, Government of India. Retrieved 8 May from http://nsap.nic.in/disbursementAbstract. do?methodName=viewStateReport

Munro, L. T. (2008). Risks, need and rights: Compatible or contradictory bases for social protection. In A. Barrientos \& D. Hulme (Eds.), Social protection for the poor and poorest: Concepts, policies and politics (pp. 27-46). Palgrave Macmillan UK. https://doi.org/10.1057/978-0-230-58309-2_2

Nanda, S. (2019). Love and marriage: Cultural diversity in a changing world. Waveland Press.

Pellissery, S. (2008). Process deficits in the provision of social protection in rural Maharashtra. In A. Barrientos \& D. Hulme (Eds.), Social protection for the poor and poorest: Concepts, policies and politics (pp. 227-246). Palgrave Macmillan UK. https://doi.org/10.1057/978-0-230-58309-2_12 
Polkinghorne, D. E. (1995). Narrative configuration in qualitative analysis. International Journal of Qualitative Studies in Education, 8(1), 5-23. https://doi.org/10.1080/0951839950080103

Ram, F., Mohanty, S. K., \& Ram, U. (2009). Understanding the distribution of BPL cards: All-India and selected states. Economic and Political Weekly, 44(7), 66-71. https://www. jstor.org/stable/40278510

Riessman, C. K. (2000). Stigma and everyday resistance practices: Childless women in south India. Gender \& Society, 14(1), $111-$ 135. https://doi.org/10.1177/089124300014001007

Ritchie, J., \& Spencer, L. (2002). Qualitative data analysis for applied policy research. In A. M. Huberman \& M. B. T. Miles (Eds.), The qualitative researcher's companion (pp. 305-329). Sage. https://doi.org/10.4135/9781412986274

Rosenheim, M. K. (1966). Vagrancy concepts in welfare law. California Law Review, 54(2), 511-566.

Sewell, W. H. (1999). The concept(s) of culture. In V. Bonnell \& L. Hun (Eds.), Beyond the cultural turn: New directions in the study of society and culture (pp. 35-61). University of California Press.

Sinha, A., Lombe, M., Saltzman, L. Y., Whetten, K. Whetten, R., \& Positive Outcomes for Orphans Research Team. (2016). Exploring factors associated with educational outcomes for orphan and abandoned children in India. Global Social Welfare, 3(1), 23-32. https://doi.org/10.1007/s40609-016-0043-7

Ugargol, A. P., Hutter, I., James, K. S., \& Bailey, A. (2016). Care needs and caregivers: Associations and effects of living arrangements on caregiving to older adults in India. Ageing International, 41(2), 193-213. https://doi.org/10.1007/s12126016-9243-9

United Nations Department of Economic and Social Affairs (UNDESC). (2007). Social protection, labour and work. In The employment imperative: Report on the world social situation 2007. United Nations.

United Nations Economic and Social Council. (2001). Report of the Secretary General to the Thirty-ninth Session E/CN.5/2001/2. https://undocs.org/E/CN.5/2001/9

Vera-Sanso, P. (2004). “They don't need it, and I can't give it”: Filial support in South India. In P. Kreager \& E. Schröder-Butterfill (Eds.), Ageing without children: European and Asian perspectives on elderly access to support networks (pp. 77-105). Berghahn Books.

Wertz, F. J., Charmaz, K., McMullen, L. M., Josselson, R., Anderson, R., \& McSpadden, E. (2011). Five ways of doing qualitative analysis: Phenomenological psychology, grounded theory, discourse analysis, narrative research, and intuitive inquiry. Guilford. http://ebookcentral.proquest.com/lib/auckland/detail. action?doc ID $=674984$

\section{History}

Received May 28, 2020

Accepted September 11, 2020

Published online October 21, 2020

\section{Acknowledgments}

The authors wish to thank Dr. R. Anitha, Dr. S. Ponni, and Dr. R. Hemalakshmi for their contributions to the research project, and Dr. U. R. Kaliappan for his insights and comments on the article.

\section{Conflict of Interest}

The authors declare no conflict of interest.

\section{Author Note}

Vanessa Burholt is now at the School of Nursing/School of Population Health, Faculty of Medical and Health Sciences, University of Auckland, New Zealand.

\section{Editorial Note}

The acting editor was Isabelle Albert.

\section{Funding}

This work was supported by Health and Care Research Wales Senior Research Leader Fund.

\section{ORCID}

Vanessa Burholt (iD) https://orcid.org/0000-0002-6789-127X

\section{Vanessa Burholt}

School of Nursing

Faculty of Medical and Health Sciences

The University of Auckland

85 Park Road

Grafton

Private Bag 92019

Auckland

New Zealand

vanessa.burholt@auckland.ac.nz 